This is an Open Access article distributed under the terms of the Creative Commons Attribution 4.0 International License

ORIGINAL ARTICLE

\title{
THE RELATIONSHIP BETWEEN PROCEDURE AND SUPERVISION ON THE QUALITY OF MEDICAL RECORD IN IMELDA HOSPITAL
}

\section{Zulham Andi Ritonga1, Ida Yustina, Destanul Aulia²}

1 Student of Masters of Public Health, Universitas Sumatera Utara,

2 Lecturer of Faculty of Public Health, Universitas Sumatera Utara, Prof. Maas Street, USU

Campus, Medan, Indonesia,

* Correspondence: zulhamandi16@gmail.com

\begin{abstract}
The quality of an excellent medical record must meet the indicators of completeness and accuracy of filling, timeliness in safety, and provision of medical records that meet legal requirements. The study aimed to examine the relationship between procedures and supervision on the quality medical records for inpatient. A survey study approach was applied in this study and the research conducted at the Imelda Hospital. We stratified random sampling to select 100 samples, including 21 doctors, 65 nurses, and 14 medical records officers. The results showed that the procedure factor did not affect the quality of medical records at the Imelda Hospital, p-value 0.520>0.05. The controlling factor influences the quality of medical records at Imelda Hospital, p-value $0.001<0.05$. Hospitals need to implement routine monitoring that is evaluated on an ongoing basis to achieve high-quality medical records.
\end{abstract}

Keywords: medical record quality of Inpatient Care, Supervision, Procedure

International Journal of Nursing and Health Services (IJNHS), September 2019, Volume 2, Issue 3; Page 180-188

Received: 27 June 2019; Revised: 19 July 2019; Accepted: 23 July 2019

DOI: http//doi.org/10.35654/ijnhs.v2i3.230

\section{Introduction}

Hospital is one of the health care facilities per person in improving the health status of the community by the health development goals in Indonesia. The development of science and technology influences the system of change in society which demands quality health services. According to the Hospital Accreditation Committee, a critical parameter in meeting the requirements and health requirements in hospitals is data or information from medical records. Medical records must meet the completeness criteria, accuracy, time, and fulfill legal obligations (1). University of Muhammadiyah Hospital Malang, from the results of the analysis, 40 medical records provided were not complete $100 \%$ (2).

Besides, it also based on an analysis of 102 inpatient medical records for the June 2016 period at Dr. Mental Hospital. Soeharto Heerdjan Jakarta obtained an average percentage of completeness of $49.4 \%$ (3). Furthermore, the analysis of the integrity of 
filling inpatient medical record files at the Medan Hajj Hospital found that the level of completeness of medical records averaged $60 \%$ (4).

According to the Ministry of Health (2008), the standard medical record completeness must be $100 \%$. The medical record is said to be complete is completed by health personnel in less than 24 hours after completion of outpatient or inpatient services. Incomplete medical records have an impact on health services providing, data processing, costing, protecting legal interests for patients, hospitals, and health workers (5).

Inaccuracies in filling medical records found in Ungaran Hospital Semarang, from the results of the analysis of 312 inpatient documents, there were percentage rates of the accuracy of coding reaching 74.67\% (6). Also, PKU Muhammadiyah Hospital in Sukoharjo Surakarta, from 250 medical records, there are inaccuracies in writing diagnoses of obstetric cases 162 medical records (64.8\%) (7).

Other medical record quality indicators can be assessed from the accuracy of the medical record return time and patient waiting time at registration. This problem was found in several hospitals, including Wates Yogyakarta Hospital, of the 164 medical records, there were 63 files (38\%) inaccurate returns to medical records (5). Besides that, Tk Hospital. III Dr. Reksodiwiryo Padang obtained the average waiting time of patients in the registration section is 26 minutes 22 seconds.

An earlier study showed that delays in returning medical records to the storage room could cause delays in service to patients, resulting in a decrease in the quality of health services (8). Other medical record quality indicators can be assessed from the accuracy of the medical record return time and patient waiting time at registration. This problem was found in several hospitals, including Wates Yogyakarta Hospital, of the 164 medical records, there were 63 files (38\%) inaccurate returns to medical records (9). Besides that, Tk Hospital. III Dr. Reksodiwiryo Padang obtained the average waiting time of patients in the registration section is 26 minutes 22 seconds (10). An earlier study showed that delays in returning medical records to the storage room could cause delays in service to patients, resulting in a decrease in the quality of health services (11).

Imelda Indonesian Workers' Hospital is a type B private hospital in Medan that received Intermediate Accreditation from KARS in February 2017. Based on the reporting of patient visits in 2017, there were 73,745 patients, consisting of outpatients 58,294 and hospitalizations 15,447 . The average number of outpatient visits in one month was 4,858 patients, and 1,287 patients were hospitalized (12).

A preliminary survey conducted in September 2018 at Imelda Indonesian Workers Hospital, from an analysis of 30 inpatient medical records, there were complete fillings of $78.5 \%$ and incomplete $21.5 \%$. The charging accuracy is $85 \%$ and inaccurate $15 \%$. Calculation of the time of the return of 30 inpatient medical records after the patient returns to the storage rack; it is known that the average length of back is 4.78 days. The results of the calculation of waiting time in 50 inpatients in the medical record file service in the registration section, on average, there are 35.16 minutes.

Following the background description above regarding the issue of quality medical records, the authors are interested in researching the effect of procedures and supervision on the quality of medical records at Imelda Indonesian workers Hospital 


\section{Objective}

The study aimed to examine the relationship between the procedures and supervision on the quality of inpatient medical records at RSU Imelda Indonesian Workers

\section{Method}

A survey study was appllied to examine the relationship between the procedures and supervision on the quality of inpatient medical records at RSU Imelda Indonesian Workers. The study was conducted at the Imelda Indonesian Workers' Hospital Medan. One hundred samples were recruited using the stratified random sampling by dividing the population into proportional homogeneous (strata) groups, namely 21 people, 65 nurses, and 14 medical records, from each random sample. Data collection in this study by interview using a questionnaire. The chi-square test and multivariate analysis were used to analyze the data

\section{Result}

4.1 Distribution of respondents characteristics in Imelda Indonesian Workers Hospital

Table 1. Distribution of respondents characteristics in Imelda Indonesian Workers Hospital

\begin{tabular}{lcc}
\hline \multicolumn{1}{c}{ Characteristics } & $\mathbf{n}$ & $\mathbf{\%}$ \\
\hline Age & & \\
$\quad<33$ years old & 55 & 55.0 \\
$\quad>33$ years old & 45 & 45.0 \\
Sex & & \\
$\quad$ Male & 21 & 21.11 \\
$\quad$ Female & 79 & 79.79 \\
Marital status & & \\
$\quad$ Married & 56 & 56.66 \\
$\quad$ Single & 44 & 44.44 \\
Length of work & & \\
$\quad<8$ years & 58 & 58.58 \\
$\quad>8$ years & 42 & 42.42 \\
Occupation & & \\
$\quad$ Diploma of nurse & 62 & 62.62 \\
$\quad$ Bachelor of nurse & 21 & 21.11 \\
$\quad$ Medical doctor & 16 & 16.16 \\
Receiving medical record & & \\
training & & \\
$\quad$ Yes & 17 & 17.17 \\
$\quad$ No & 83 & 83.83 \\
\end{tabular}

The results showed that the average age of respondents was 33 years with the lowest age of 20 years and the highest age of 56 years. Most respondents aged $<33$ years were 55 people $(55.0 \%)$, while respondents aged $>33$ years were 45 people $(45.0 \%)$. Based on gender, the majority of respondents were female as many as 79 people $(79.0 \%)$, a small 
portion was male as many as 21 people (21.0\%). Majority of respondents married (56.0\%), a small percentage of unmarried respondents were 44 people (44.0\%).

The duration of work is based on the Decree of the Head of the State Civil Service Agency (BKN) Number 11 of 2002 with a calculation of 8 years. The results of this study were mostly respondents working $<8$ years as many as 58 people $(58.0 \%)$, while those who worked $>8$ years were 42 people $(42.0 \%)$. Based on education, most of the respondents were educated D3 (diploma) as many as 62 people (62.0\%), a small proportion had an education S2 (specialist) as many as 17 people (17.0\%). Most respondents had never attended medical record training (83.0\%), only a small proportion of respondents had participated in medical record training $(17.0 \%)$.

\subsection{Distribution of procedure Category in Imelda Indonesian Workers Hospital}

\begin{tabular}{|c|c|c|}
\hline Characteristics & $\mathbf{n}$ & $\%$ \\
\hline \multicolumn{3}{|l|}{ Procedure of hospital } \\
\hline Good & 57 & 55.0 \\
\hline Less & 43 & 45.0 \\
\hline \multicolumn{3}{|c|}{ Supervision implementation } \\
\hline Good & 65 & 65.65 \\
\hline Less & 35 & 35.35 \\
\hline \multicolumn{3}{|l|}{ Quality of medical record } \\
\hline Good & 56 & 56.56 \\
\hline less & 44 & 44.44 \\
\hline \multicolumn{3}{|l|}{ Completeness of medical } \\
\hline $\begin{array}{l}\text { Complete } \\
\text { Incomplete }\end{array}$ & 42 & 42.42 \\
\hline \multicolumn{3}{|c|}{ Occuracy of medical record } \\
\hline Occurate & 90 & 90.90 \\
\hline Not occurate & 10 & 10.10 \\
\hline \multicolumn{3}{|l|}{ Collecting in time } \\
\hline $\begin{array}{l}<2 \text { days } \\
>2 \text { days }\end{array}$ & 13 & $\begin{array}{l}81.81 \\
13.13\end{array}$ \\
\hline \multicolumn{3}{|l|}{$\begin{array}{l}\text { Compliance with legal } \\
\text { requirements }\end{array}$} \\
\hline $\begin{array}{l}\text { requirements } \\
\text { Fulfilled }\end{array}$ & 89 & 89.89 \\
\hline Unfulfilled & 11 & 11.11 \\
\hline
\end{tabular}

The results of the study showed more than 50 percent of hospital procedures were categorized as proper procedures, while a small proportion of respondents stated in the lousy category as many as 43 people (43.0\%). Regarding supervision in the hospital, the majority of respondents conducted proper control (65.0\%). Around 35\% have not carried out monitoring properly.

The results showed that the majority of the quality of medical records at the Indonesian Labor Hospital Imelda was in a suitable category (56.0\%). But some of the quality of medical records is still low (44.0\%). Based on observations from 100 medical 
records that have completed the service, it shows that most of the medical records were filled in completely (68.0\%). Only about $32.0 \%$ are incomplete. Based on the accuracy of the medical record, it shows that from the analysis of 100 medical record forms, the accurate filling was 90 medical records $(90.0 \%)$, and inaccurate as many as ten medical records $(10.0 \%)$.

Based on the accuracy of the time to return the medical record file shows that most of the medical record returns on time $(<2$ days) $(87.0 \%)$. But some are late returning medical records ( $>2$ days) $(13,0 \%)$. The calculation of medical records as compliance with legal requirements shows that the majority of medical records meet legal obligations $(89.0 \%)$.

4.3. Relationship between health professional and quality of medical record

\begin{tabular}{ccccccc}
\hline & \multicolumn{5}{c}{ Quality of medical record } & \\
\cline { 2 - 6 } Profesi & \multicolumn{2}{c}{ good } & \multicolumn{2}{c}{ less } & & \\
\cline { 2 - 6 } & $\mathrm{n}$ & $\%$ & $\mathrm{n}$ & $\%$ & $\mathrm{~N}$ & $\%$ \\
\hline RM officer & 12 & 85,7 & 2 & 14,3 & 14 & 100,0 \\
Doktor & 15 & 71,4 & 6 & 28,6 & 21 & 100,0 \\
Nurse & 29 & 44,6 & 36 & 55,4 & 65 & 100,0 \\
\hline
\end{tabular}

The results of the cross table related to the quality of medical records show that of the 14 medical records officers studied, most of them filled out the medical records well. Two of them did not fill in completely (14.3\%). Of the 21 doctors studied, most of the quality in filling out their medical records in the top category were 15 people (71.4\%), as many as six people in the less group (28.6\%). Likewise, of the 65 nurses who studied most of the medical records filling quality in the less category as many as 36 people (55.4\%), as many as 29 people in the excellent class (44.6\%)

\subsection{Relationships between procedure and supervision with the quality of medical records in Imelda Indonesian Workers Hospital}

\begin{tabular}{|c|c|c|c|c|c|c|c|}
\hline \multirow{3}{*}{ Variable } & \multicolumn{4}{|c|}{ Medical Record Quality } & \multirow{2}{*}{\multicolumn{2}{|c|}{ Total }} & \multirow{3}{*}{$p$-value } \\
\hline & \multicolumn{2}{|c|}{ Good } & \multicolumn{2}{|c|}{ Less } & & & \\
\hline & $\mathrm{n}$ & $\%$ & $\mathrm{n}$ & $\%$ & $\mathrm{~N}$ & $\%$ & \\
\hline \multicolumn{8}{|l|}{ Procedure } \\
\hline Good & 34 & 34,0 & 23 & 23,0 & 57 & 57,0 & 0,520 \\
\hline Less & 22 & 22,0 & 21 & 21,0 & 43 & 43,0 & \\
\hline \multicolumn{8}{|l|}{ Supervision } \\
\hline Good & 45 & 45,0 & 20 & 20,0 & 65 & 65,0 & 0,001 \\
\hline Less & 11 & 11,0 & 24 & 24,0 & 35 & 35,0 & \\
\hline
\end{tabular}


Based on the results of the cross table shows that there is a relationship between proper medical record procedures with the quality of medical records. Of the 43 respondents who stated that the medical record procedure was not the majority, the quality of medical records in the proper category was 22 people $(22.0 \%)$.

Statistical test results using the chi-square test on Continuity Correction obtained p-value $0.0520>0.05$. This shows that there is no significant relationship between the procedure and the quality of medical records at Imelda. Indonesian Workers Hospital.

The results presented in the table also show that of the 65 respondents, 45 respondents stated that the supervision of the medical record was appropriate. Of the 35 respondents who said that the monitoring of medical records was less than the majority, the quality of medical records in the category was less than 24 people $(24.0 \%)$.

Statistical test results using the chi-square test on Continuity Correction obtained a p-value of $0.001<0.05$. This shows that there is a significant relationship between supervision and the quality of medical records. At the Indonesian worker Imelda Hospital

\subsection{Double Logistic Regression Test Results}

\begin{tabular}{lcccc}
\hline Variable & B & Sig. & Exp (B) & 95\%CI for Exp (B) \\
\hline Supervision & 1,679 & 0,001 & 5,359 & $1,968-14,594$ \\
A constant & $-1,749$ & 0,001 & & \\
\hline
\end{tabular}

Multiple logistic regression test showed that the supervision variable affected the quality of medical records at the Indonesian Labor Hospital Imelda, which was p-value $0.001<0.05$

\section{Discussion}

The Effect of Supervision on Medical Record Quality in Imelda Indonesian Workers Hospital

Based on the results of the study indicate that there is a significant influence between the supervision of the quality of medical records in the Imelda Indonesian Workers' Hospital 2019, p-value $=0.001<0.05$. The supervisor variable has an Exp value $(B)=5.359(95 \% \mathrm{CI}=1.968-14.594)$. This shows that supervision has been 5.3 times more likely to have good medical records at the Indonesian workers' Hospital, Imelda.

Based on the results of this study indicate that the supervision carried out by superiors on health workers (medical record officers, doctors, nurses) in filling inpatient medical records at the Imelda Indonesian Workers' Hospital had a significant effect on the quality of medical records at Imelda Indonesian Workers Hospital.14 The influence of these two relationships shows that proper supervision by the supervisor will improve the quality of the inpatient medical record. Conversely, lack of control causes the quality of medical records to be reduced. The perceived oversight by respondents caused an incomplete medical history to create incomplete medical records (15) 
In this study, it showed that the supervision at the Imelda Indonesian Workers Hospital was carried out by the committee and the head of the medical record by conducting direct control. Direct supervision by guiding health workers before starting work appeals to health workers who are not disciplined in filling medical records for both outpatients and inpatients. Monitoring is also carried out by providing time to conduct briefings and evaluate the quality of the implementation of medical records. Although not done, this effort routinely is to minimize errors in filling medical records (16)

Supervision relating to the quality of medical records which is conducted once a month by the Indonesian Workers Hospital Imelda discusses the problems faced in completing medical records.

\section{The Procedure Does Not Affect the Quality of Medical Records in Imelda Indonesian Workers Hospita}

Based on the results of the study showed that there was no effect of the procedure on the quality of inpatient medical records at the Imelda Indonesian Workers' Hospital in $2019, \mathrm{p}=0.520>0.05$. The process does not affect the quality of the inpatient medical record. This is because the data distribution does not show differences between respondents who state that the medical record procedure is proper to those who report that the medical record procedure is lacking. Both groups showed that the majority of respondents recorded outstanding medical records. However, this method is not suitable for implementing good quality medical records.

The results showed that the procedure for managing medical records by health workers at the Indonesian Workers' Hospital Imelda did not affect the quality of the inpatient medical record at Imelda. The system for managing inpatient medical records at the Indonesian Workers' Hospital Imelda is through the process for patients coming to the inpatient department based on a letter of request from a doctor, emergency department, or referral from another hospital.

The medical record file is sent by the officer, together with the patient to the room in question. The officer then accepts the patient and records into a register which consists of a history of the disease, and the results of other examinations are recorded in the medical record sheet and signed. Nurses/midwives add medical record sheets according to the services provided.17 Nurses/midwives make daily censuses of patient mutations from 00.00 to 24.00 . This is made three copies to be sent to the inpatient room as an archive. Data is sent to the medical record unit, and one at the place of admission for inpatients (18).

Then the room clerk checks the medical record before sending it to the medical record unit. After the patient returns home, the officer sends the medical record file back to the medical record unit no later than 24 hours (19). The medical record unit staff processes the complete data included in the disease index card, operating index, death index to make reports, and Hospital statistics. Medical record officers recapitulate every month (20). The medical record unit keeps a medical record file according to the number. When adopting a centralized system, the data for each patient are put together. 


\section{Conclusions}

In conclusion, there is a positive correlation between procedure and supervision on the quality of medical record at Indonesian worker Imelda Hospital.

\section{References}

1. Regulation of the Minister of Health. Regulation of the Minister of Health of the Republic of Indonesia Number 55 Year 2013 concerning the Implementation of Medical Recording Work. Jakarta, Ministry of Health of the Republic of Indonesia. 2013

2. Hospital Accreditation Commission (HAC). Hospital Accreditation Instrument Accreditation Standards Version 2012. Edition 1, Jakarta. 2012

3. Nurhaidah, Harijanto T, Djauhari T. Factors Causing the Incompleteness of Inpatient Medical Record Filling in the University Hospital of Muhammadiyah Malang. Brawijaya Medical Journal. 2017; 29 (3).

4. Pamungkas TW, Triyani M, Solikhah. Analysis of Incompleteness in Filling in Medical Records at PKU Muhammadiyah Hospital in Yogyakarta. Jakarta, Journal of Public Health, 2010.

5. Manihuruk MW. Completeness Analysis of Inpatient Medical Record File Filling in Medan Haji Hospital. Faculty of Public Health, Universitas Sumatera Utara Press. 2016.

6. Ministry of Health of the Republic of Indonesia. Minister of Health Regulation Number 55 Year 2013 Regarding the Implementation of Medical Recording Work. 2013

7. Windari, Kristijono. Analysis of Coding Accuracy Produced by Koder in RSUD Ungaran. Semarang. Journal of Health Polytechnic Health Research Semarang. 2016; 5 (1): 24611026.

8. Maryati, W. Relationship between the Accuracy of Writing a Diagnosis and the Accuracy of the Obstetrics Diagnosis Code Case at PKU Muhammadiyah Sukoharjo Hospital. Journal of Infokes. 2016; 6(2): 2086 - 2628.

9. Maharsi NZ. Level of Timeliness of Returning Inpatient medical record files at Wates Hospital Yogyakarta. Health Recording and Health Information Study Program General Achmad Yani. 2017

10. Elsa F. Analysis of the Waiting Time of Medical Record Services in the Outpatient Registration of Kindergarten Hospitals. III Dr. Reksodiwiryo Padang. Universitas Andalas Press. 2016.

11. Fauziah AA. Completeness Analysis of Inpatient Hospital Medical Records File Filling in DR. Esnawan Antariksa Halim Perdana Kusuma Jakarta. Fakultas Kesehatan Masyarakat Universitas Indonesia. 2014

12. Imelda Indonesian Workers General Hospital. Profile of the Indonesian Labor Imelda General Hospital. Medan, IPI Hospital. 2018

13. Imelda Indonesian Workers General Hospital. Report on Patient Visits at the Indonesian Worker Imelda General Hospital. Medan, IPI Hospital. 2018. 
14. Pourasghar F, Malekafzali H, Koch S, Fors U. Factors Influencing the Quality of Medical Documentation When a Paper-Based Medical Records System is Replaced with an Electronic Medical Records System: An Iranian Case Study. International Journal of Technology Assessment in Health Care, 2008; 24(4): 445-451. 2008.

15. Gasperz Z. Total Quality Management (Mold 2). Jakarta, Gramedia Main Library. 2010

16. Garvin DA. Managing Quality. New York, The Free Press. 1998

17. Hutama H, \& Santosa E. Evaluation of Medical Record Quality at PKU Hospital 1 Muhammadiyah Yogyakarta: Case Study in Caesarian Sectio Patients. Journal of Medicoeticolegal and Hospital Management, 5 (1), 25-34. 2016.

18. Saravi BM, Asgari Z, Siamian H, Farahabadi EB, Gorji AH, Motamed N, Mohammadi R. Documentation of Medical Records in Hospitals of Mazandaran University of Medical Sciences: A Quantitative Study. Acta Informatica Medica. 2016; 24(3): 202-206. 2016.

19. Krishna SSS. (2011). Application: Medical Record. Jakarta, FKM University of Indonesia.

20. Miska KEM, Kumitawa A, \& Kumwenda B. Factors Affecting the Utilisation of Eletronic Medical Records System in Malawian Central Hospitals. Malawi Medical Journal. 2017; 29 (3): 247-253. 